time would be both substantial and durable. The spandrils and abutments may be constructed of such materials as could be most readily obtained, and which was considered suitable, as such bridges admit of being finished similar to a stone one or otherwise, according to the taste of the projectors and resources of the locality.

\title{
On the Application of Water Pressure, as a Motive Power, for working
}

Cranes and other kinds of Machinery. By Mr. W. G. Armstrong, F. R. S., Assoc. Inst. C. E.*

The object of the paper was to direct attention to the advantages of a more extended application of hydraulic pressure as a motive power, and to point out the means of attaining this desirable end; illustrating the arguments by descriptions and drawings of the engines on this principle already erected since the year 1845 , when the author first designed a crane to be worked by the pressure of water from the street water pipes, at Newcastle-upon-Tyne.

The principle of these engines, as applied to cranes, was described to be very simple. In order to lift a weight, the water, under a pressure of about 100 feet head or more, being admitted through a slide valve into a cylinder, exerted a force on a piston, whose rod was connected with the hoisting chain, so arranged by passing over several pulleys, as to increase its length of travel to the requisite duty to be performed; the piston receding from the pressure therefore raised the weight to the height required. The lowering of the weight was accomplished by a reverse action, and the crane was turned in either direction by a similar action of a smaller cylinder, whose piston rod was connected with a rack, working into a circle of teeth, fixed to the base of the movable frame of the crane.

The action of these machines was described to be very smooth and steady, ingenious appliances being adopted for obviating the shock that would otherwise be caused by the sudden closing of the slide valves, and all the different operations being under the perfect control of a few regulating handles. In cases of a great diversity of power being required separate cylinders were used, so arranged as that their action could be combined according to the force required. The speed of working had no other limit than the size of the supply pipe.

Allusion was made to the advantage of employing hydraulic pressure in mercantile docks, for hoisting heavy weights, for whipping light goods out of ships, and for opening and shutting dock gates, swing bridges, and sluices. Its facility of transmission, its safety, and constant readiness for use, rendered its peculiarly suitable for these purposes. It would generally be preferable in such cases to employ steam power to force the water, rather than to be dependent upon town water works; and a tank upon a tower, or upon an eminence, would form a convenient magazine of power, enabling the engine to act continuously with an uniform load. Large air ressels had also been successfully employed instead of an elevated tank.

Hydraulic pressure might also, in many cases, be advantageously em. ployed for purposes requiring continuous rotation. There were many

* From the London Civil Engineer and Architect's Journal, for June, 1850. 
natural situations where mountain streams might be arrested, or surface water be impounded on elevated ground, and be conveysd by a pipe into a neighboring valley, where great mechanical efficiency might be derived from a small supply of water by the use of water pressure engines. In mining operations, also, the danger and inconvenience of underground steam engines might be obviated by substituting water pressure engines, conveying the water down the shaft in pipes, and returning it to the surface, by the action of the pumping engine above ground. In such cases the water was merely the vehicle for transmitting power into the mine.

A water pressure engine had been lately very successfully applied by the author in South Hetton Colliery, for the traction of wagons upon an underground railway. Similar engines had also been erected in the lead mines at Allenheads, for lifting ore and other purposes. Reservoirs were there formed upon the neighboring hills, and pipes were carried into the mines to supply the engines, the expended water flowing out by a level. Other engines of the same description were also in course of erection, for surface operations, at the same place, such as crushing ore and raising minerals from the shafts.

In their general character, these engines were similar to reciprocating steam engines. The slide valves were balanced by equal pressures in opposite directions, and were constructed to open very spacious water passages. The liability to concussion, on the closing of the eduction port, was obviated by the application of relief valves, which were lifted by the compressive action of the piston, causing it to act for an instant as a pump, in forcing back the opposing water into the supply pipe. In cases where the engines had been applied to hauling or winding, four cylinders placed diagonally in pairs had been used. In other cases two cylinders had been applied, the uniformity in the motion of the column being maintained by a loaded plunger. The winding engines were reversed by a slot link apparatus, similar to that of a locomotive engine, and which was worked by the pressure of the water, acting under the control of a valve. The regulating and reversing valves were each placed at the mouth of the shaft, at a distance from the engine, the operation of which could thus be directed with great accuracy and safety.

The drawings which accompanied the paper gave representations of an hydraulic crane, for shipping coals at Glasgow; hydraulic platform cranes, at the railway station, Newcastle-upoh-Tyne; hydraulic hoisting machines, at the warehouses of the Albert Docks, Liverpool; a water pressure engine for a crushing mill at Allenheads; a similar engine used at the same place for winding, and numerous details of all these machines.-Proc. Inst. Civ. Eng., May 7, 1850.

\section{Steam Haulage on Rivers and Canals.*}

An experiment has lately been tried, with complete success, on the Gloucester and Berkely Canal, of a somewhat novel steam tug for hauling vessels instead of horse power. It consists of a continuous flexible rail or bar of iron running the whole length of the canal, and made fast at each

* From the London Civil Engineer and Architect's Journal, for June, 1850. 